\title{
O MUNDO NEGRO DE SALVADOR EM TRANSFORMAÇÃO: LEITURA DE UMA CONSCIÊNCIA CRÍTICA AFRODESCENDENTE EM AÇÃO
}

PINHO, Osmundo Santos de Araujo. O mundo negro: hermenêutica crítica da reafricanização em Salvador. Curitiba: Editora Progressiva/Núcleo de Estudos Afro-Brasileiros da Universidade Federal do Recôncavo da Bahia, 2010. 492p.

\begin{abstract}
A preender analiticamente o vasto, maravilhoso e complexo mundo negro da Bahia não é tarefa fácil. Mas, quando se trata de abordar, de forma articulada, os universos do candomblé, do carnaval, os movimentos negros, as relações sociais e raciais, aspectos da cultura, do cotidiano, dos mundos do trabalho e da estética da juventude negra de Salvador, numa perspectiva hermenêutica que leva em conta a história, a historiografia e os diversos debates teóricos envolvidos, a tarefa se transforma num verdadeiro desafio que, se não impossível, poderia parecer, à primeira vista, muito ambicioso.
\end{abstract}

Desse ponto de vista, o magnífico trabalho de Osmundo Pinho aparece como uma verdadeira performance, realizada com muita maestria e uma qualidade inquestionável. Tendo realizado, alguns anos atrás, uma pesquisa ${ }^{1}$ sobre $o$ tema do carnaval negro de Salvador, foi com imenso prazer que adentrei seu livro, versão "sem maiores alterações substantivas" (p. 5) da tese

Franck Ribard, Le Carnaval noir de Bahia. Identité, ethnicité et fête afro à Bahia, Paris: L'Harmattan, 1999. de doutorado, defendida em 2003, no Programa de Pós-Graduação em Ciências Sociais da Unicamp. ${ }^{2}$

O objeto principal da pesquisa, que se desmembra em várias questões, toma como ponto de partida o argumento central do livro Carnaval ijexá, hoje clássico, de Antonio Risério, publicado em 1981, ${ }^{3}$ que apontava o processo de "reafricanização" como uma chave de leitura das novas dinâmicas do que foi chamado de movimento afro-baiano e, em particular, do carnaval tomado como foco da observação. A partir dessa premissa e da construção da reafricanização, das suas narrativas, apreendidas como "objeto para uma reflexão crítica", Osmundo Pinho opera uma leitura "histórico-processual" de seus contextos, ramificações, reproduções, conexões, como um modo de fazer uma "revisão compreensiva dos estudos sobre afrodescendentes em Salvador, assim como uma maneira de

A tese, pela qualidade da argumentação e da escrita, teria merecido, a meu ver, uma melhor revisão formal e de edição, evitando múltiplas incorreções que poluem o texto. Antônio Risério, Carnaval Ijexá: notas sobre afoxés e blocos do novo carnaval afrobaiano, Salvador: Corrupio, 1981. 
tentar propor um entendimento mais abrangente do processo" (p. 15).

Nessa perspectiva, o autor vislumbra fazer emergir o mundo negro reafricanizado como um objeto possível, que, mesmo disperso e descentrado, não deixa de constituir um "mundo, antes de mais nada". "Filho da terra", pertencente a esse mundo, revela que a sua desconstrução crítica, bem como a sua textualização, "aberta e não codificada", a sua interpretação correspondem a formas de participar dele e, de algum modo, de transformá-lo, em nome de uma "crítica afrodescendente que, sagrada pelo sol da liberdade, clama por reconhecimento e transformações" (p.433), como afirma na última frase do livro.

Contudo (não existe trabalho perfeito na subjetividade do leitor!), a força do trabalho - a sua capacidade de operar um olhar "macro" sobre um período longo, articulando vários níveis de discussão - expõe a análise a certas limitações, inerentes aos recortes. Assim, a definição prévia desse mundo negro reafricanizado, a partir dos elementos abordados, mesmo que reapresentados e descontruídos, obedece a um recorte um tanto tautológico em relação à linha geral do raciocínio destinado a demonstrá-lo e a interpretá-lo. Se a argumentação é brilhante, pautada numa vivência essencial, nos resultados de um trabalho de campo probante e de um conhecimento ímpar das pesquisas realizadas sobre os diferentes temas abordados, a hipótese geral dessa reafricanização perene e diversa desde a década de 1970 (certamente uma temporalização mais detalhada da "reafricanização" no período abordado teria ajudado) não é sempre convincente quando se olha o conjunto das dimensões constitutivas desse processo.

$\mathrm{Na}$ mesma linha de pensamento, a falta de pesquisa empírica e de fontes primárias em certos temas abordados, apesar da riqueza do diálogo estabelecido com a bibliografia existente e colocada como modus operandi do trabalho, enfraquece a argumentação geral. Talvez a preeminência de múltiplas orientações e discussões conceituais e teóricas, que às vezes tornam-se o centro da análise em detrimento da pesquisa empírica, não sirva, apesar de ser um trabalho de tese, à coerência do raciocínio geral da pesquisa.

O livro é composto de uma introdução, quatro capítulos e uma conclusão. Depois de uma introdução clara e rica, que anuncia a natureza do objeto, os pressupostos teóricos e a estrutura da tese, conforme já descritos, Osmundo Pinho aborda, no capítulo 1 , a trajetória histórica da subordinação racial na Bahia. Analisando o vínculo entre classe e raça, na perspectiva de apreender a reprodução da posição desigual do negro no mercado e na divisão social do trabalho e pôr em foco as lutas de classes racializadas em Salvador, o caminho se inicia com a discussão clássica e muito debatida da natureza das relações raciais no Brasil. 
Historicizando, a partir da bibliografia consagrada, a economia baiana (talvez melhor: soteropolitana), são estabelecidas diversas temporalidades dando conta do processo de transformação dessa sociedade, da sua estrutura ocupacional no trabalho, e da questão do "status", para chegar, a partir da década de 1950, à criação do Polo Petroquímico, à industrialização e modernização durante o Regime Militar (1960-1980) e, finalmente, a partir dos anos 1990, à hiperinflação, ao Plano Real e à abertura da economia. A retrospectiva histórica - sustentada, para o período mais recente, por numerosos dados quantitativos nem sempre analisados — estabelece a permanência e a reintrodução da desigualdade racial no processo de formação das classes na longa transição de "uma Bahia tradicional e subdesenvolvida para uma outra, que é a mesma, moderna e industrializada" (p.64), revelando a força do passado escravocrata, cujos efeitos são sentidos no presente. Segue uma reflexão teórica sobre a formação das identidades de classe e o lugar das "race formations", na qual a história social (Thompson, Benjamin) e os estudos culturais ingleses (Gilroy, Hall) auxiliam a percepção do papel importante da anterioridade histórico-cultural na formação das classes e do campo das práticas e lutas de classe e de seu peso no contexto das identidades e das culturas populares. Esse argumento é aproveitado para estabelecer a relação entre a reafri- canização e as novas identidades afrodescendentes em Salvador. As coisas se complicam quando se trata de examinar as correlações possíveis entre as noções de raça e de classe (esta última tomada como pressuposto conceitual mas não definida de modo operacional no contexto abordado), a partir da emergência do movimento afro-baiano, cristalizada em torno da narrativa do Ilê Aiyê, de seus fundadores, empregados do Polo Petroquímico que ascenderam como membros da "classe média", mas que foram rejeitados pela "classe dominante", e a partir, de forma mais ampla, da constituição de um "operariado negro" abordado, sobretudo a partir de Agier, Guimarães e Castro. ${ }^{4} \mathrm{~A}$ análise, pautada não só no exame das identidades (de classe e de raça), mas sobretudo no enfoque do contexto que indique as interconexões entre o mundo da vida cotidiana (onde se expressa a racialização) e o mundo descrito em termos macro-histórico e econômico, entre infra- e superestrutura, aproximando "práticas de raça" e "práticas de classe", tende a estabelecer os mecanismos que determinam a "nossa anulação política simultânea à subalternização cultural e a expropriação econômica" (p.91).

Retomando, no capítulo 2, o argumento já presente em Antonio Risério, qual seja a centralidade do

Antônio Sergio Guimarães, Michel Agier e Nadya Araujo Castro (orgs.), Imagens e identidades do Trabalho, São Paulo: HUCITEC/ORSTOM, 1995. 
lugar do candomblé - guardião da ancestralidade e encarnando a "anterioridade" — e do modelo jeje-nagô na fundamentação da cultura e dos mundos negros baianos, Osmundo Pinho percorre o longo caminho, desde a figura emblemática do Ogeladê Martiniano Eliseu do Bonfim, das tramas históricas e historiográficas que fizeram do candomblé um elemento primordial da reafricanização. É notável, nesse sentido, a abrangência do percurso argumentativo. Elenca as figuras fundadoras (garantia da perenidade e da manutenção do sagrado), os momentos e a trajetória da articulação da tradição, as dimensões organizacionais, políticas e rituais dos terreiros (como não homogeneizar!) e o princípio estruturante, "mágico" e vital do axé e propõe, fundamentalmente, operar uma reinterpretação da genealogia, das narrativas fomentadores da tradição religiosa afro-baiana. Apreendendo as principais questões da formação do campo dos estudos afro-brasileiros e afro-baianos, ligadas em particular aos temas da miscigenação e da assimilação, que produziram as "raças" e o "problema negro", revela também as confluências, as promiscuidades de discursos e as manipulações recíprocas e "multi-sentidos" existentes entre os intelectuais e o povo de santo, sobretudo a partir dos congressos afro-brasileiros. A partir dos anos 1950, com a profissionalização das ciências sociais e os desdobramentos do Ciclo da Unesco, o debate se orienta em busca das correlações culturais entre o Brasil e a África, da "mentalidade africana" e da ideia de uma cultura de resistência. Se essas ideias certamente podem ser compreendidas como integrando o conjunto das discursividades da reafricanização, o autor tem razão em enfatizar a existência de outras construções discursivas, tal como a ideia de "baianidade" que coabitaria no mesmo contexto. Caracterizada como ideologia, "como forma total e absoluta de interpretar a realidade" (p.208), a baianidade apresenta-se com contornos totalitários, mascara a realidade sociorracial em prol de uma imagem homogeneizadora de consensualidade e de tolerância que seria o resultado natural da miscigenação, amplamente divulgada no modelo do Produto Cultural Bahia explorado pela indústria cultural. Do meu ponto de vista, a genealogia dessa ideologia aponta, inclusive, para um mecanismo de neutralização, de cooptação, mais fundamentalmente de controle, por parte dos segmentos políticos, midiáticos e da indústria cultural ligados à elite econômica baiana, face à emergência do movimento afro-baiano e da chamada reafricanização, percebidos como uma ameaça clara à hierarquização social e racial da cidade.

Resta que o candomblé - matriz simbólica, coração da cultura negra, fonte do repertório de uma "reafricanização em vários níveis" cuja narrativa concreta teria seu fundamento de ancestralidade asso- 
ciada ao bairro da Liberdade e à Ladeira do Curuzu (outras narrativas, ligadas a outros espaços?) - constitui um elemento central para a análise e compreensão da arena principal e determinante da reafricanização, o carnaval, abordado no capítulo 3. Discutindo o espaço da festa, o autor continua na sua lógica de leitura crítica da trajetória do debate acadêmico. Apreende as controvérsias teóricas que visam, fundamentalmente, à definição da natureza do espaço do carnaval e à sua relação com a sociedade. Essas controvérsias, de maneira clássica, oscilam entre análises que privilegiam a perspectiva simbólica e ritualística (Da Matta ${ }^{5}$ ) e os trabalhos fundamentados na influência nacional e histórica do modelo carioca (Pereira de Queiroz ${ }^{6}$ ). Com o objetivo de perceber as especificidades da festa em Salvador, a historicização da trajetória carnavalesca afro-soteropolitana desde o final do século XIX apresenta-se como outro ponto importante do capítulo. Assim, tomando o carnaval como um duplo da sociedade, no qual ela se transforma pela abertura à invenção e à aventura de uma identidade cultural em formação e pelo caráter performático do ritual, descreve a formação e a reinvenção do carnaval negro em Salvador, desde os clubes negros oitocentistas até,

Roberto Da Matta, Carnavais, malandros e heróis: para uma sociologia do dilema brasileiro, Rio de Janeiro: Zahar, 1981.

6 Maria Isaura Pereira de Queirós, Carnaval brasileiro: o vivido e o mito, São Paulo: Brasiliense, 1999. bem mais recentemente, os blocos afros, todos considerados, apesar de separados no tempo, como organizações que se reinventam em torno do "Signo-África" (p.256). A narrativa genealógica dos blocos afros, da sua ligação com os afoxés e os blocos de índio, do papel pioneiro do Ilê Aiyê e de Vovô (José Carlos dos Santos), dos desdobramentos que deram lugar ao Olodum e ao Muzenza, não oferece muita originalidade, de certa forma reificando imagens consagradas que, a meu ver, reproduzem uma visão centralizadora ao extremo no seio dos discursos hegemônicos da tradição. A linguagem, de fato, e o campo discursivo, dialógico e conflitivo, representado pelas músicas, costumes, nomes dos blocos afros e afoxés, a sua institucionalização, produções e temas carnavalescos estão no centro desse lugar da tradição africana que se apresenta também como estratégia de resistência, constituindo um novo sujeito: "o negro, como um homem novo", rompendo com as formações discursivas racializadas dominantes e fruto de "posições de sujeito" enunciadas e da ação performática: agência e performance, agência como performance.

Essa ruptura no carnaval negro, operada pela performance das identidades afrodescendentes na reafricanização, aparece na análise como um processo de autorrepresentação aberto e suplementado pelo Signo-África. Ela implica uma fratura semiótica e abre novos caminhos, possibilidades de vir a ser, "discur- 
sos híbridos e ambivalentes, críticos e contra-hegemônicos" que extrapolam o espaço restrito do carnaval em direção à globalização cultural, inclusive da cultura negra, ao mundo dos "objetos comodificados" e à cultura de consumo, envolvendo a produção de "subjetividades sob condições da modernidade" (p.304).

A problemática da reafricanização encontra, então, no resto do capítulo 3 , tensões cruciais quando, adentrando na dinâmica das produções identitárias negras envolvidas e expressando-se na trama do consumo e da participação (alienante) do mundo das mercadorias, revela a lógica do "detournement" (Debord ${ }^{7}$ ) afrodescendente que, nas práticas performativas, estabelece o style (por exemplo, do "Mano Brau") e alimenta-se dos "campos culturais conexos", como o reggae, o funk e o pagode. É verdade que, nos anos 1990-1995, a "explosão" da indústria cultural pautada na midiatização globalizada a partir, sobretudo, do impacto das expressões negras do carnaval que, fenômeno crucial, foi capitalizado pela "montagem" do axé-music - e a consolidação do mercado turístico festivo de Salvador atingiram patamares impressionantes, provocando deslocamentos (desterritorialização?) e gerando novas posturas, expressões, mensagens e discursos da juventude negra imergida // imersa // nas identidades globais. No entanto, essa diversidade, que reúne elementos

Guy Debord, A sociedade do espetáculo, Rio de Janeiro: Contraponto, 1998. de "raiz", posturas politizadas e produções meramente voltadas para o mercado, mesmo configurando uma riqueza cultural baiana complexa, não deixa, a meu ver, de interrogar sobre a possibilidade de enxergar a "reafricanização", nesse novo contexto, em termos de uma diluição do seu sentido ou, então, concomitante a uma fragmentação irredutível em vários mundos negros.

Osmundo Pinho, por sua vez, busca superar, em sua análise, a questão da heterogeneidade (às vezes, quase antagônica) das identidades e dos discursos negros na reafricanização. Para isso, ele introduz a problemática central do "corpo negro reinventado" como "re-invenção da Paisagem da Cidade de Salvador" (p.341). Assim, nas lógicas do gesto e do organismo-corpo negros, revelando a subversividade do corpo negro que é também "fronteira variável e em disputa", emergem, entre outros, figuras de gênero reafricanizadas tais como o "Mano Brau", a "Beleza Negra", o que possibilita a análise crítica de outros ícones estereotipados da mulher negra como a "mulata", a "bahiana do Acarajé" ou a "empregada doméstica". A reafricanização aparece, então, como uma "máquina de guerra", no sentido deleuziano, invenção e revolta nômade que desterritorializa e reinventa um mundo, identidades, subjetividades e devires articulados em torno do Signo-África, opondo-se à centralização de um aparelho de Estado que se esforça em capturar e seques- 
trar o seu potencial contaminante e proliferante. $\mathrm{O}$ ponto chave desse enfrentamento, fazendo eco à oscilação de um movimento que explora sua multiplicidade nômade, mas que experiencia também uma "centralização congelante", remete, do ponto de vista da urgência política e social da transformação da sociedade baiana (e brasileira!), à consolidação de uma atividade consciente em que a "Consciência Insurgente e crítica da Representação" (tema do último capítulo) surge como leme importantes dessa luta.

Abre-se, então, a última parte do livro. A partir da recuperação e da articulação das premissas anteriores, desenvolve-se uma argumentação final pautada na valorização e no reconhecimento dessa consciência insubordinada, rebelde e crítica que, insurgindo-se contra as representações raciais hegemônicas e a subalternização do negro, deve trabalhar para "a aurora de um novo dia no qual o 'sol da liberdade' brilhe para todos" (p.360). A análise dessa luta histórica e política, que é também o processo inconcluso do protagonismo, da emergência de novos sujeitos negros, da construção de identidades afrodescendentes, leva o autor a abordar, de maneira mais específica, a trajetória e as narrativas sobre a organização política no "meio negro". Partindo da narrativa emancipatória de longa duração que se ancora na resistência secular e na ideia fundadora do quilombo de Palmares, na figura heroica de Zum- bi, nas quais vão se juntando a resistência escrava e a luta abolicionista, a argumentação acompanha a emergência, numa continuidade autoproclamada, do movimento negro moderno, em particular do Movimento Negro Unificado (MNU). Nessa longa e intensa jornada, surgem momentos, organizações e figuras essenciais (a Frente Negra, Abdias do Nascimento e o Teatro Experimental do Negro...) que balizam a genealogia e explicam, no contexto da redemocratização pós-ditatura militar e da profusão das expressões culturais e militantes, a emergência dos novos atores sociais negros em torno do MNU. Esse processo, nada simples, encontra desdobramentos específicos em Salvador, onde o projeto político e de inspiração/interpretação claramente marxista - marca registrada de um MNU começando e dos movimentos de esquerda da década de 1980 — teve de compor e muitas vezes foi tencionado pela força de uma mobilização popular ancorada na tradição e numa afirmação cultural negra e afro-baiana que não se reconhecia, de forma geral, nas figuras e no discurso teórico de uma vertente percebida e associada a uma intelectualidade negra, distante do cotidiano dos bairros onde se ancorava a maioria dos blocos afros e afoxés. Essa característica baiana, ligada a um processo de reafricanização pautado numa "reinvenção da cidade como territórios negros", se manifestou particularmente nas mensagens comunitárias dos blocos 
afros representando seus bairros de origem, "performando" nos diferentes espaços públicos e centralizados da cidade no carnaval, nas festas de largo e no Pelourinho, espaço recriado como "coração da negritude baiana".

Osmundo Pinho insiste, de forma pertinente, na importância estratégica da politização e da "racialização" do espaço público e das relações "sócio-espaciais", por meio das performances, da reinvenção da visualidade corporal e da afirmação de uma representação positivada dos negros e de suas práticas culturais que, "desterritorializando" e produzindo lugares simbólicos/territoriais (verdadeiros territórios negros), enfrentam e criam alternativas à exclusão histórica da esfera pública.

Por fim, a diversidade das narrativas negras de interpretação e ação políticas - envolvendo o legado da luta histórica pela libertação; o contexto mais recente trazendo a problemática identitária, os embates da relação público/privado e as tensões entre perspectivas marxistas e culturalistas - parece contribuir para o caráter múltiplo de um movimento negro em Salvador marcado pelos desdobramentos da reafricanização. A convergência desses elementos aponta, por sua vez, para uma "consciência insurgente", identificada com as raízes do "protesto negro" e que constitui uma plataforma histórica, território de articulação discursiva do sujeito político afrodescendente.
Nesses termos, a emancipação negra passaria tanto pela libertação do negro de si, como pela afirmação da sua negritude, pela emergência de uma consciência negra como forma de identificação racial coletiva rompendo com o status quo colonial que inferioriza o negro. Aparece, assim, a oscilação presente entre "afirmar-se racialmente e negar o racismo". Para o autor, essa problemática remete à questão da descolonização intelectual como etapa de emancipação racial em que a formação de intelectuais "subalternos" garantiria a emergência de uma crítica subalterna. Dialogando com os estudos da subalternidade na Índia e na América Latina, a antropologia crítica norte-americana e os estudos culturais britânicos sobre o tema da representação da subalternidade, ele desenvolve uma análise do papel do intelectual negro ou "de cor", a partir de sua posição de sujeito. No contexto brasileiro, esse diálogo revela as tensões com o campo cientifico que, por exemplo, segundo Alberto Guerreiro Ramos, exotizou o negro na sociologia dos estudos afro-brasileiros, fazendo dele uma "peça de museu" e criando, enquanto objeto de estudos, na Bahia, de imensa maioria negra, o "Problema Negro".

Essas reflexões finais, que enfatizam também as críticas recíprocas e a desconfiança existentes entre a "militância negra", a "esquerda organizada" e a "academia", abrem-se em direção à reafirmação do caráter fundamental de uma consciência 
afrodescendente crítica, insubordinada e rebelde, que "se insurge contra as formas hegemônicas de representação racial e subalternização do negro" (pp. 431-32). As diversas formas, parte integrante do processo de reafricanização, que a consciência política assume no ativismo negro, na reflexão intelectual crítica, na atividade de investigação universitária, são associadas a uma posição de sujeito afrodescendente espelhada na dinâmica de "reconstituição de si assim como um reencontro com a História" (p.432).
Osmundo Pinho termina seu belo trabalho se permitindo, naquele momento, revelar uma dimensão muitas vezes subentendida mas, finalmente, tão presente no seu texto e no conjunto da sua linha argumentativa: O Mundo Negro da Bahia é o seu mundo, e a tarefa a que ele procurou "devotar" seu trabalho pode ser entendida como uma participação, uma contribuição, um engajamento pessoal com a crítica afrodescendente, clamando pela necessidade do "reconhecimento e de transformações", digo eu, por um mundo melhor.

Franck Ribard fribard@yahoo.com Universidade Federal do Ceará 